\title{
Escleritis nodular por neurosífilis en paciente inmunocompetente. Reporte de caso
}

\section{Nodular scleritis caused by neurosyphilis in an immunocompetent patient. Case report}

\author{
José D. Paulo ${ }^{1,2 *}$, Isabel C. Gómez-Suárez² y Diana C. Montoya-Carrasquilla ${ }^{2}$ \\ ${ }^{1}$ Servicio de Oftalmología, Hospital Pablo Tobón Uribe, Universidad de Antioquía; ${ }^{2}$ Departamento de Oftalmología, Universidad Pontificia Bolivariana. \\ Medellín, Colombia.
}

\section{Resumen}

Caso clínico: Mujer de 59 años con escleritis nodular en quien, al no tener respuesta al tratamiento con antiinflamatorios no esteroideos orales y corticoide oral y tópico, se ordenaron estudios paraclínicos que mostraron VDRL reactivo en 32 dls y FTA ABS en suero reactivo. Se realizó punción lumbar que evidenció pleocitosis. Con este resultado se diagnosticó escleritis nodular secundaria a neurosífilis y se inició tratamiento con penicilina intravenosa, con lo cual se obtuvo mejoría del cuadro clínico. Discusión: El compromiso escleral por sífilis es poco común, y menos aún si es la única manifestación ocular; sumado a esto, la mayoría de los reportes de escleritis como manifestación de sífilis se han descrito en personas con infección por el VIH, a diferencia del presente caso, en el cual no hay inmunocompromiso y la serología para el VIH fue negativa.

Palabras clave: Esclera. Sifilis. Enfermedades de la esclera. Uveítis. Inflamación ocular.

\section{Abstract}

Case report: A 59-year-old woman with nodular scleritis without improvement after oral treatment with non-steroidal anti-inflammatory drugs, and oral and topical corticosteroids. Tests were performed finding reactive VDRL in 32 dls and reactive FTA-ABS. A lumbar puncture evidenced pleocytosis. Nodular scleritis secondary to neurosyphilis was diagnosed and treatment with intravenous penicillin was initiated, showing improvement of scleral inflammation. Discussion: Scleritis due to syphilis is uncommon, and even more so if it is the only ocular manifestation. In addition, most reports of scleritis as a manifestation of syphilis have been described in people with HIV infection, but our patient was not immunocompromised, and HIV serology was negative.

Key words: Sclera. Syphilis. Scleral diseases. Uveitis. Ocular inflammation.

\section{Introducción}

La escleritis, que es la inflamación del plexo vascular profundo adyacente a la esclera, comprende un cuadro clínico caracterizado por ojo rojo con apariencia cercana al color violáceo debido a la profundidad de las estructuras inflamadas, edema que compromete la

Correspondencia:

*José D. Paulo

Carrera 43 29-35, consultorio 713

Fecha de recepción: 02-05-2020

Fecha de aceptación: 10-07-2020

DOI: 10.24875/RMO.M21000170
Disponible en internet: 01-07-2021 Rev Mex Oftalmol. 2021;95(4):171-174

www.rmo.com.mx 
esclera y dolor que aumenta con los movimientos oculares y la palpación'. En 1976, Watson y Hayreh² propusieron un sistema de clasificación que permanece vigente hasta la fecha: anatómicamente se reconoce la escleritis anterior como la inflamación que ocurre por delante de la inserción de los músculos rectos, la cual a su vez puede ser difusa, nodular, necrotizante con signos de inflamación y necrotizante sin signos de inflamación (escleromalacia perforans); la inflamación que ocurre por detrás de la inserción de los músculos rectos se conoce como escleritis posterior, que puede ser difusa o nodular.

A diferencia de la epiescleritis, la escleritis se ha asociado de forma más frecuente a trastornos sistémicos. Se estima que más del $50 \%$ de los casos de escleritis se presentan en el contexto de una enfermedad sistémica autoinmunitaria, siendo la artritis reumatoide la más prevalente, seguida de las vasculitis y las espondiloartropatías seronegativas. La forma de presentación de la inflamación tiene un papel importante en la probabilidad de asociación a condiciones sistémicas, siendo menos graves la escleritis difusa y nodular, y de mayor gravedad las necrotizantes, con o sin signos de inflamación, casos en los que el $80 \%$ pueden asociarse a enfermedad sistémica, en mayor proporción granulomatosis con poliangeítis".

Respecto a la etiología infecciosa, se presenta en el 4-10\% de los pacientes con escleritis, y la infección por virus herpes zóster es la causa infecciosa más frecuente.

En el contexto de un trauma o una cirugía ocular, el microorganismo que más se asocia a escleritis infecciosa posoperatoria es Pseudomonas aeruginosa, causante del $28-67 \%$ de los casos $^{3}$. Sin embargo, se han relacionado muchos otros patógenos como causa de infección escleral, entre ellos Borrelia burgdorferi, Mycobacterium tuberculosis y Acanthamoeba. En casos aislados en pacientes con infección por VIH con inmunosupresión se ha reportado Treponema pallidum, siempre con manifestaciones sistémicas asociadas ${ }^{4,5}$.

A continuación se describe un caso de presentación atípica de escleritis infecciosa.

\section{Caso clínico}

Mujer de 59 años, ama de casa, con antecedentes de hipertensión arterial controlada con losartán. Ha sido manejada por varios años en el servicio de oftalmología por diagnóstico de ojo seco evaporativo moderado, con mejoría parcial con colirios lubricantes, y por hipermetropía y presbicia que mejoran con la corrección con lentes.

Consulta al servicio de oftalmología general por presentar un cuadro de 1 mes de evolución de dolor ocular en el ojo izquierdo asociado a ojo rojo sin cambios en la agudeza visual, por el cual venía siendo manejada con diclofenaco oral con mejoría parcial de los síntomas. Al examen ocular se encuentra una agudeza visual corregida de 20/20 en ambos ojos, y en el ojo izquierdo se aprecia en la esclera un nódulo vascularizado, levantado, de localización temporal superior, que no aclara con fenilefrina. Se encuentran además inyección conjuntival, córnea con tinción punteada inferior y un tiempo de rotura de la película lagrimal acortado. La presión intraocular era de $14 \mathrm{mmHg}$ en ambos ojos, el cristalino estaba transparente y el fondo de ojo no presentaba hallazgos anormales.

Se realiza diagnóstico de escleritis nodular anterior, primer episodio, y se inicia tratamiento con antiinflamatorios no esteroideos orales junto con corticoide oral y tópico, sin mejoría de la sintomatología después de 2 semanas de tratamiento. Adicionalmente, se ordenan estudios paraclínicos (Tabla 1) que reportan VDRL (Venereal Disease Research Laboratory) reactivo en 32 dls y FTA ABS en suero reactivo, por lo cual es remitida a neurología clínica, donde ordenan punción lumbar, y la determinación VDRL en el líquido cefalorraquídeo (LCR) fue negativa, pero se evidenció pleocitosis. Con este resultado se decide hospitalizarla con diagnóstico de escleritis nodular secundaria a neurosífilis para tratamiento con penicilina cristalina, 4.000 .000 UI cada 4 horas. Un mes después de la hospitalización, en el control oftalmológico, se encuentra una agudeza visual sin cambios, con una esclera sin lesiones, con mejoría clínica de los signos inflamatorios y resto del examen ocular sin cambios con respecto al previo. En el estudio de LCR 3 meses posterior al tratamiento se evidenció una disminución completa de leucocitos en el LCR, así como títulos bajos de VDRL en suero (1:2 dls). La paciente del presente reporte no presentó otras manifestaciones de neurosífilis diferentes del cuadro inflamatorio ocular.

\section{Discusión}

El compromiso ocular por sífilis puede presentarse en cualquiera de los estadios, siendo la iritis y la coriorretinitis las formas oculares más frecuentes; se calcula que ocurre en el $2.5-5 \%$ de los pacientes que progresan a las formas secundaria y terciaria. Una serie de casos publicada por Barile y Flynn ${ }^{6}$ encontró que el 
Tabla 1. Exámenes de laboratorio realizados al no evidenciar mejoría de la escleritis

\begin{tabular}{|c|c|}
\hline Paraclínicos & Resultado (valor de referencia) \\
\hline Radiografía de tórax & Cambios bronquíticos leves \\
\hline PCR (mg/dl) & $0.4(0-10)$ \\
\hline Leucocitos (células/ $\mu l$ ) & $5830(4500-11,000)$ \\
\hline Neutrófilos (\%) & $47.9(55-68)$ \\
\hline Linfocitos (\%) & $41(23-38)$ \\
\hline Hemoglobina $(\mathrm{g} / \mathrm{dl})$ & $14.6(12-16)$ \\
\hline Hematocrito (\%) & $44.7(36-48)$ \\
\hline Factor reumatoideo (UI/ml) & $64(<60)$ \\
\hline ANA & Negativo \\
\hline P-ANCA & Negativo \\
\hline C-ANCA & Negativo \\
\hline VIH (ELISA) & Negativo \\
\hline AgsHB (UI/I) & $<0.10(<0.1-0.99)$ \\
\hline VDRL (suero) & Reactivo 1:32 dls \\
\hline FTA - ABS (suero) & Positivo \\
\hline Citoquímico de LCR & $\begin{array}{l}\text { Aspecto claro } \\
\text { Color normal } \\
\text { Bacterias no se observan } \\
\text { Leucocitos } 10 / \mathrm{mm}^{3}\left(0-5 / \mathrm{mm}^{3}\right) \\
\text { PMNN } 1 / \mathrm{mm}^{3}\left(0 / \mathrm{mm}^{3}\right) \\
\text { Mononucleares } 9 / \mathrm{mm}^{3}\left(0-5 / \mathrm{mm}^{3}\right) \\
\text { Eritrocitos } 0 / \mathrm{mm}^{3}\left(0 / \mathrm{mm}^{3}\right) \\
\text { Proteínas } 35.8 \mathrm{mg} / \mathrm{dl}(15-45 \mathrm{mg} / \mathrm{dl}) \\
\text { Glucosa } 47 \mathrm{mg} / \mathrm{dl}(40-80 \mathrm{mg} / \mathrm{dl})\end{array}$ \\
\hline VDRL en LCR & No reactivo \\
\hline \multicolumn{2}{|c|}{$\begin{array}{l}\text { AgsHB: antígeno de superficie de la hepatitis B; ANA: anticuerpos antinucleares; } \\
\text { C-ANCA: anticuerpos anticitoplasma del neutrófilo patrón citoplasmático; } \\
\text { ELISA: enzyme-linked immunosorbent assay; FTA-ABS: prueba de absorción de } \\
\text { anticuerpos treponémicos fluorescentes; LCR: líquido cefalorraquídeo; } \\
\text { P-ANCA: anticuerpos anticitoplasma del neutrófilo patrón perinuclear; } \\
\text { PCR: proténa C reactiva; PMNN: polimorfonucleares neutrófilos; VDRL: venereal } \\
\text { disease research laboratory; VIH: virus de la inmunodeficiencia humana. }\end{array}$} \\
\hline
\end{tabular}

4.3\% de los pacientes atendidos por uveítis tuvieron inflamación ocular atribuida a infección por T. pallidum, y la forma de presentación fue iridociclitis granulomatosa en el $46 \%$, iridociclitis no granulomatosa en el $25 \%$, panuveítis en el $13 \%$, uveítis posterior en el $8 \%$ y queratouveítis en el $8 \%$. Otra serie de casos más reciente ${ }^{7}$ describió la forma de presentación de la sífilis ocular en pacientes coreanos sin coinfección por el virus de la inmunodeficiencia humana $(\mathrm{VIH})$, en la que se encontró uveítis posterior en el $38 \%$ de los casos, panuveítis en el $29 \%$ y neuritis óptica en el $11 \%$; el compromiso de estructuras del segmento anterior diferentes del iris solo se dio en dos pacientes (4.4\%) en la forma de queratitis intersticial, y no hubo casos de escleritis ni de epiescleritis.

Según los datos anteriores puede concluirse que el compromiso escleral por sífilis es poco común, y menos aún si es la única manifestación ocular. Sumado a esto, la mayoría de los reportes de escleritis como manifestación de sífilis se han descrito en personas con infección por el VIH, a diferencia del presente caso, en el que no había inmunocompromiso y la serología para el VIH fue negativa.

Fénolland, et al. ${ }^{8}$ describieron el caso de un hombre de 47 años con escleritis anterior nodular unilateral asociado a uveítis anterior no granulomatosa, vitreítis leve y vasculitis retiniana focal en la zona de la escleritis. La serología para sífilis y VIH fue positiva, el tamizaje para neurosífilis fue negativo y el cuadro inflamatorio ocular se resolvió con el tratamiento con penicilina $\mathrm{G}$.

De igual forma, en 2013, Lee, et al. ${ }^{5}$ reportaron el caso de un hombre de 45 años con diagnóstico previo de infección por el VIH que se presentó con escleritis anterior difusa asociada a vitreítis y retinitis hemorrágica. La reacción en cadena de la polimerasa en humor acuoso fue negativa para virus, mientras que la serología RPR fue positiva. Se consiguió la mejoría del cuadro clínico después de 5 días de tratamiento.

El compromiso escleral en personas con infección por el VIH es independiente de los valores de CD4 e incluso puede aparecer en la etapa de reconstitución autoinmunitaria, como reportaron Moloney, et al. ${ }^{4}$ en 2004 al describir un caso de escleritis nodular en un paciente con VIH cuyos títulos de CD4 previos fueron $12 \times 10^{9} \mathrm{cel} / \mathrm{l}$ y en el momento del cuadro inflamatorio ocular, después de 18 meses de terapia antirretroviral, eran $340 \times 10^{9} \mathrm{cel} / \mathrm{l}$, y además con positivización de las pruebas treponémicas que en el estudio basal fueron negativas.

En lo referente al compromiso escleral o epiescleral por sífilis en personas inmunocompetentes, en Corea del Sur se reportó el caso de una mujer de 62 años con epiescleritis recalcitrante en la que la prueba VDRL fue reactiva (1:32), y en el estudio de LCR se encontró pleocitosis $\left(10 / \mathrm{mm}^{3}\right)$ y VDRL reactivo (1:2). El cuadro se resolvió en la primera semana de tratamiento ${ }^{9}$. Este caso es el más similar al del presente reporte y describe la asociación de compromiso escleral por sífilis con afectación del sistema nervioso central en una persona inmunocompetente, lo cual indica que esta etiología debe considerarse en todo tipo de pacientes, ya que el tratamiento antibiótico específico es determinante para la mejoría del cuadro. 
La neurosífilis es difícil de diagnosticar porque no tiene un patrón característico de presentación. En ausencia de contaminación con sangre del LCR, la VDRL es muy específica, pero su sensibilidad es del $67-72 \%$ y un resultado negativo no la descarta. En el presente caso, a pesar del resultado negativo de VDRL en el LCR, la reactividad serológica confirmada con una prueba no treponémica (VDRL) y una prueba treponémica (FTA-ABS), sumada al compromiso ocular y la pleocitosis en el LCR, constituyen criterios de diagnóstico de neurosífilis ${ }^{10,11}$.

Cualquier forma de sífilis ocular debe ser tratada como neurosífilis con penicilina cristalina en dosis de 18-24 millones de UI al día por 10-14 días, por vía intravenosa, dividida en seis dosis. El tratamiento con penicilina benzatínica no se recomienda por no alcanzar concentraciones terapéuticas en el LCR ${ }^{11}$. La paciente del presente reporte fue tratada por neurosífilis y mostró mejoría del cuadro clínico y de los exámenes de laboratorio.

\section{Conclusión}

En todas sus etapas, la sífilis puede causar compromiso ocular variable, en la mayoría de los casos como uveítis posterior con o sin neuritis óptica; la afectación de estructuras del segmento anterior se ha descrito en varios reportes como queratitis intersticial. La escleritis por esta causa es poco común, se requiere la sospecha clínica e incluirla siempre en el tamizaje diagnóstico, reconocer que la infección por T. pallidum puede ser causa de los síntomas incluso en pacientes sin $\mathrm{VIH}$ y sin otra manifestación oftalmológica, y descartar siempre otras causas infecciosas (las más frecuentes en la escleritis son las autoinmunitarias). Una vez establecida la asociación, la resolución de los síntomas con el tratamiento de neurosífilis confirma la etiología del cuadro.

\section{Conflicto de intereses}

Los autores del presente reporte de caso declaran que no existen conflictos de intereses en su divulgación.

\section{Responsabilidades éticas}

Protección de personas y animales. Los autores declaran que para esta investigación no se han realizado experimentos en seres humanos ni en animales.

Confidencialidad de los datos. Los autores declaran que han seguido los protocolos de su centro de trabajo sobre la publicación de datos de pacientes.

Derecho a la privacidad y consentimiento informado. Los autores han obtenido el consentimiento informado de los pacientes y/o sujetos referidos en el artículo. Este documento obra en poder del autor de correspondencia.

\section{Bibliografía}

1. Daniel Diaz J, Sobol EK, Gritz DC. Treatment and management of scleral disorders. Surv Ophthalmol. 2016;61:702-17.

2. Watson PG, Hayreh SS. Scleritis and episcleritis. Br J Ophthalmol. 1976;60:163-91

3. Doshi RR, Harocopos GJ, Schwab IR, Cunningham ET. The spectrum of postoperative scleral necrosis. Surv Ophthalmol. 2013;58:620-33.

4. Moloney G, Branley M, Kotsiou G, Rhodes D. Syphilis presenting as scleritis in an HIV-positive man undergoing immune reconstitution. Clin Experiment Ophthalmol. 2004;32:526-8.

5. Lee SB, Kim KS, Lee WK, Kim YJ, Kang MW. Ocular syphilis characterised by severe scleritis in a patient infected with HIV. Lancet Infect Dis. 2013;13:994.

6. Barile GR, Flynn TE. Syphilis exposure in patients with uveitis. Ophthalmology. 1997; 104:1605-9.

7. Kim Y, Yu S-Y, Kwak HW. Non-human immunodeficiency virus-related ocular syphilis in a Korean population: clinical manifestations and treatment outcomes. Korean J Ophthalmol KJO. 2016;30:360-8.

8. Fénolland J-R, Bonnel S, Rambaud C, Froussart-Maille F, Rigal-Sastourné J-C. Syphilitic scleritis. Ocul Immunol Inflamm. 2016;24:93-5.

9. Yoon K-C, Im S-K, Seo M-S, Park Y-G. Neurosyphilitic episcleritis. Acta Ophthalmol Scand. 2005;83:265-6.

10. Marra CM, Maxwell CL, Tantalo L, Eaton M, Rompalo AM, Raines C et al. Normalization of cerebrospinal fluid abnormalities after neurosyphilis therapy: does HIV status matter? Clin Infect Dis. 2004;38:1001-6.

11. Syphilis - 2015 STD Treatment Guidelines. 2019. (Consultado el 17 de junio de 2020.) Disponible en: https://www.cdc.gov/std/tg2015/syphilis.htm 